\title{
Anxiety-Behavior Modulated by Ventral Medial Prefrontal Cortex of Rats Submitted to the Vogel Conflict Test Involves a Local NMDA Receptor and Nitric Oxide
}

\author{
Sabrina F. Lisboa, Francisco S. Guimarães, Leonardo B. M. Resstel* \\ Department of Pharmacology, School of Medicine of Ribeirão Preto, \\ University of São Paulo, Ribeirão Preto, Brazil \\ E-mail: "leoresstel@yahoo.com.br \\ Received March 30, 2011; revised April 18, 2011; accepted April 25, 2011
}

\begin{abstract}
It was demonstrated in the Vogel conflict test (VCT) that the ventral portion of medial prefrontal cortex (vMPFC) of rats is involved with anxiety behavior. Moreover, the vMPFC local glutamatergic and nitrergic system interaction is involved in modulation of fear conditioning, a model of anxiety. To better understand the role of the MPFC-glutamatergic and nitrergic system on the VTC behavior response, male Wistar rats $(250 \mathrm{~g})$ were water deprived for $48 \mathrm{~h}$ before the VCT. After $24 \mathrm{~h}$ of water deprivation, they were subjected to an initial 3-min non-punished (pre-test) drinking session. Twenty-four hours later bilateral microinjections of NMDA-antagonist LY235959 (4 nmol/200 nL), the specific nNOS inhibitor N-Propyl-L-arginine (N-Propyl $-0.08 \mathrm{nmol} / 200 \mathrm{~nL}$ ), the NO scavenger Carboxi-PTIO (C-PTIO, $2 \mathrm{nmol} / 200 \mathrm{~nL}$ ) or $200 \mathrm{~nL}$ of vehicle were applied in the vMPFC. After $10 \mathrm{~min}$, the animals were submitted to 3-min punished-licking session. LY235959 increased the number of punished licks. Similar to LY235959, both N-Propyl and C-PTIO also increased the number of punished licks. No changes were observed when LY235959, N-Propyl and C-PTIO were microinjected into vMPFC surrounding structures such as the cingulate cortex area 1, the corpus callosum and the tenia tecta. In control experiments these drugs did not change neither the number of unpunished licks nor had any effect in the tail-flick test. The results show that NO signaling in the vMPFC can modulate anxiety-behavior in the VCT by control punished behavior. Moreover, this NO modulation could be associated with local glutamatergic activation through NMDA receptors.
\end{abstract}

Keywords: Infra Limbic Cortex, Prelimbic Cortex, Anxiolytic-Like Effects, Defensive Behavior

\section{Introduction}

The medial prefrontal cortex (MPFC) of rats has been the focus of considerable studies, owing in part to understanding the central importance of its dysfunction in a wide array of psychopathological conditions in humans [1-3]. In rats, the MPFC is activated by exposure to a variety of anxiety provoking challenges, and can be blocked by anxiolytic benzodiazepine [4-8]. Moreover, in rodents the MPFC presents an important role on neuroendocrine, autonomic and behavioral modulation during defense reactions [6,9-11].

The ventral portion of the MPFC (vMPFC), which is composed of prelimbic cortex (PL) and infralimbic cortex (IL) [10], is particularly responsive to threat stimuli and the inhibition of its neurotransmission induces anx- iolytic-like effect accompanied by attenuated cardiovascular activity in a model of contextual fear conditioning $[4,10,12,13]$. These data show the specific importance of local vMPFC neurotransmission in responses evoked by anxiety behavior in animal model.

The Vogel conflict test (VCT) is an animal model used to study the anxiety response based on suppression of punished responses, when water-deprived rats are exposed to the conflict between licking the spout of a bottle and receiving a mild shock on the tong [14-16]. Anxiolytic drugs, such as the benzodiazepines, are able to increase the number of punished licks [14,15]. Moreover, it has recently described that local vMPFC neurotransmission is involved with anxiety-like behavior response observed in VCT [17].

It has been described that during defensive reactions, 
glutamate levels are increased in the vMPFC of rats [18]. Moreover, results from our laboratory has been demonstrated that both NMDA glutamate receptors and nitric oxide (NO) present in the vMPFC play an important role in the expression of the behavioral and cardiovascular responses observed during fear evoked by contextual conditioning [19], showing an important role of these neurotransmitters in anxiety behaviour. Therefore, it is possible that, similar to previous results, NMDA receptors and NO in the vMPFC also regulate the behavioral responses observed in the VCT. Thus, the aims of the present study were to investigate the effects of vMPFC NMDA receptors and NO inactivation in rats submitted to the VCT.

\section{Material and Methods}

\subsection{Animal Preparation}

Male Wistar rats weighing 230 - $270 \mathrm{~g}$ were used. Animals were kept in the Animal Care Unit of the Department of Pharmacology, School of Medicine of Ribeirão Preto, University of São Paulo. Rats were housed individually in plastic cages with free access to food and water and under a $12 \mathrm{~h}$ light/dark cycle (lights on at 06:30 h). The Institution's Animal Ethics Committee approved housing conditions and experimental procedures (process number: 215 - 2005).

Seven days before the experiment rats were anesthetized with tribromoethanol (250 mg/kg i.p.). After scalp anesthesia with $2 \%$ lidocaine the skull was surgically exposed and stainless steel guide cannulae (26G) were implanted bilaterally in the vMPFC using a stereotaxic apparatus (Stoelting, Wood Dale, Illinois, USA). Coordinates for cannula implantation $(\mathrm{AP}=+2.2 \mathrm{~mm} ; \mathrm{L}=2.8$ $\mathrm{mm}$ from the medial suture, $\mathrm{V}=-3.3 \mathrm{~mm}$ from the skull with a lateral inclination of $23^{\circ}$ ) were selected from the rat brain atlas of Paxinos and Watson (1997). A control group of animals had stainless steel guide cannulas implanted bilaterally into surrounding structures of the vMPFC such as the cingulate cortex area $1(\mathrm{AP}=+1.2$ $\mathrm{mm} ; \mathrm{L}=1.5 \mathrm{~mm}$ from the medial suture, $\mathrm{V}=-2.3 \mathrm{~mm}$ from the skull), the corpus callosum $(\mathrm{AP}=+1.2 \mathrm{~mm}$; $\mathrm{L}=$ $2.8 \mathrm{~mm}$ from the medial suture, $\mathrm{V}=-2.3 \mathrm{~mm}$ from the skull) and the tenia tecta(AP $=+1.2 \mathrm{~mm} ; \mathrm{L}=3 \mathrm{~mm}$ from the medial suture, $\mathrm{V}=-4.3 \mathrm{~mm}$ from the skull). Cannulae were fixed to the skull with dental cement and one metal screw.

\subsection{Drugs}

The following drugs were used: LY235959 (Tocris, Westwoods Business Park Ellisville, MO, USA), N $\omega-$
Propyl-L-arginine (Tocris, Westwoods Business Park Ellisville, MO, USA) and Carboxy-PTIO ((S)-3-Carboxy4-hydroxyphenylglicine (c-PTIO, St. Louis, Missouri, USA), morphine (Sigma, St. Louis, MO, USA), Tribromoethanol (Aldrich, St. Louis, MO, USA) and Urethane (Sigma, St. Louis, MO, USA) were dissolved in sterile artificial cerebrospinal fluid (aCSF - composition: $\mathrm{NaCl}$ $100 \mathrm{mM} ; \mathrm{Na}_{3} \mathrm{PO}_{4} 2 \mathrm{mM} ; \mathrm{KCl} 2.5 \mathrm{mM} ; \mathrm{MgCl}_{2} 1 \mathrm{mM}$; $\mathrm{NaHCO}_{3} 27$ mM; $\mathrm{CaCl}_{2} 2.5 \mathrm{mM} ; \mathrm{pH}=7.4$ ).

\subsection{Vogel Conflict Test}

The Vogel conflict test was performed in a Plexiglas box $(42 \times 50 \times 25 \mathrm{~cm})$ with a stainless grid floor. The metallic spout of a drinking bottle containing water projected into the box. The contact of the animal with the spout and the grid floor closed an electrical circuit controlled by a sensor (Anxio-Meter model 102, Columbus, USA), which produced 7 pulses/s whenever the animal was in contact with both components. Each pulse was considered as a lick and every 20 licks the animal received a $0.5 \mathrm{~mA}$ shock on the metallic drinking spout for $2 \mathrm{~s}$. The sensor recorded the total number of licks and shocks delivered during the test period. The whole apparatus was located inside a sound-attenuated cage [20].

The animals were water deprived for $48 \mathrm{~h}$ before the test. After the first $24 \mathrm{~h}$ of deprivation they were allowed to drink freely for $3 \mathrm{~min}$ in the test cage in order to find the drinking bottle spout. Some animals did not find the spout and were not included in the experiment. Twentyfour hours later the drugs were injected into the vMPFC and, after $10 \mathrm{~min}$, the animals were placed into the test box. The test period lasted for $3 \mathrm{~min}$ and the animals received a $0.5 \mathrm{~mA}$ shock every 20 licks. The number of licks and shocks delivered were registered. Although the number of shocks delivered by the system was proportional to the number of licks performed by the rat (every 20 licks, one shock), sometimes the end of the test occurred when the animal was still licking but had not yet received the next shock. So, the number of licks is usually slightly higher than one would expect considering the number of shocks.

\subsection{Water Consumption Evaluation}

The apparatus was the same used in the test above; however, the electric shock delivering system was inoperative.

\subsection{Tail-Flick Test}

The apparatus consisted of an acrylic platform with a nichrome wire coil (Insight Instruments. Brazil) main- 
tained at room temperature $\left(24-26^{\circ} \mathrm{C}\right)$. The rats were gently handled and their tails were laid across the coil. The coil temperature was then raised at $9^{\circ} \mathrm{C} / \mathrm{s}$ by the passage of electric current. The system had a cut-off time of $6 \mathrm{~s}$ to prevent tissue damage when the coil temperature approached $80^{\circ} \mathrm{C}$. The time to withdraw the tail was recorded as tail-flick latency. The electric current was calibrated to provoke this reflex within $2.5-3.5 \mathrm{~s}$ in non-treated animals $[17,20]$.

The tail-flick test was conducted in independent groups of animals receiving vehicle, LY235959, N-Propyl, cPTIO intra-vMPFC or morphine i.p.. The heating was applied to a portion of the ventral surface of the tail located between 4 and $6 \mathrm{~cm}$ from its end. The tail-flick latency was measured at 5-min intervals until a stable baseline (BL) was obtained over three consecutive trials. The latency was measured again within $30 \mathrm{~s}$ after drug administration and then at 10-min intervals for up to 40 $\min [17,20]$.

\subsection{Procedures}

Microinjections of $200 \mathrm{~nL}$ of vehicle or the specific NMDA receptor antagonist LY235959 [21,22]; the neuronal isoform nitric oxide synthase inhibitor N-Propyl $[19,23]$ or the NO scavenger Carboxi-PTIO $[19,24]$ were bilaterally injected into the vMPFC $10 \mathrm{~min}$ prior the test session. As a control for drug spread, the drugs were microinjected into vMPFC surrounding structures. All drugs were administered $10 \mathrm{~min}$ before the test. Morphine chloride $(5 \mathrm{mg} / \mathrm{kg})$, dissolved in saline, was used as a positive control in the tail-flick test (see below) and was administered $30 \mathrm{~min}$ before tail-flick evaluation.

\subsection{Histological Procedure}

At the end of the experiments the rats were anesthetized with urethane $(1.25 \mathrm{~g} / \mathrm{kg}$, i.p.) and $200 \mathrm{~nL}$ of $1 \%$ Evan's blue dye was bilaterally injected into the vMPFC as a marker of the injection sites. The chest was surgically opened; the descending aorta occluded; the right atrium severed and the brain perfused with $10 \%$ formalin through the left ventricle. The brains were post fixed for $24 \mathrm{~h}$ at $4^{\circ} \mathrm{C}$, and $40 \mu \mathrm{m}$ sections were cut with a cryostat (CM 1900, Leica, Germany). Brain sections were stained with $1 \%$ neutral red. The actual placement of the injecttion needles was identified with the help of the rat brain atlas of Paxinos and Watson (1997). Animals that received drugs outside the vMPFC were joined in an OUT group.

\subsection{Data Analysis}

The data were expressed as means \pm SEM. The number of licks and shocks were analyzed by one-way ANOVA followed by the Dunnett's post hoc test. The latency of tail withdrawal was analyzed by two way-ANOVA with treatment and time as the two factors. In case of significant interaction between these factors the groups were compared by the Bonferroni's post hoc test. Results of statistical tests with $P<0.05$ were considered significant.

\section{Results}

The injection sites and a diagrammatic representation indicating the injection sites of all drugs injection into the vMPFC are presented in Figure 1.

\subsection{Effect of Bilateral Microinjection of Vehicle, LY, N-Propyl or c-PTIO into the vMPFC on the VCT}

No changes were observed in the number of licks at the non-punished, first day of exposition to the apparatus (F3,28 $=0.7, P>0.05)$. On test day, bilateral vMPFC injection of LY $(n=8)$, c-PTIO $(n=8)$ or N-Propyl $(n=8)$ (a)

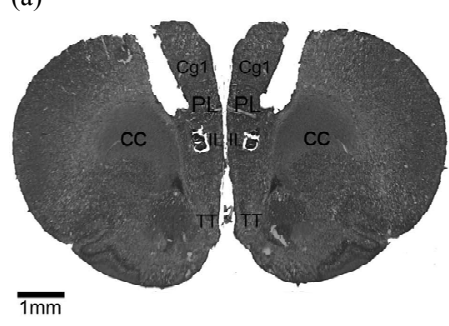

(b)

(b) $\quad \mathrm{IA}: 12$

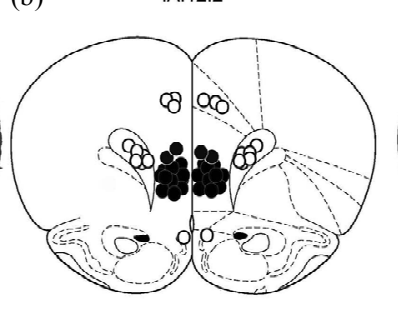

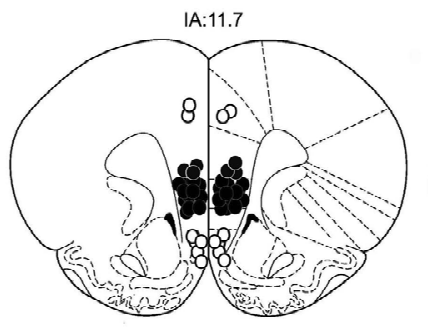

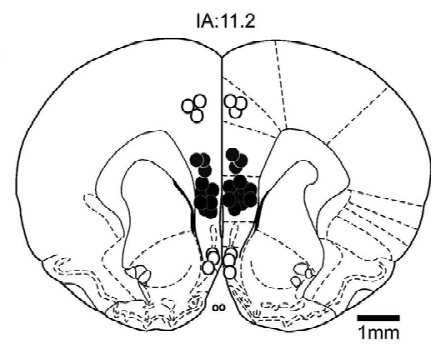

Figure 1. (a) Photomicrograph of a coronal brain section showing bilateral microinjections sites in the vMPFC. (b) Diagrammatic representation based on the rat brain atlas of Paxinos and Watson (1997) indicating the drugs sites into the vMPFC (closed circles). Animals with drug injection sites outside the vMPFC were represented by opened circles. Cg1cingulate cortex area 1; PL - prelimbic cortex; IL - infralimbic cortex; DP - dorsal peduncular cortex; cc - corpus callosum and TT- tenia tecta. IA- inter aural. 


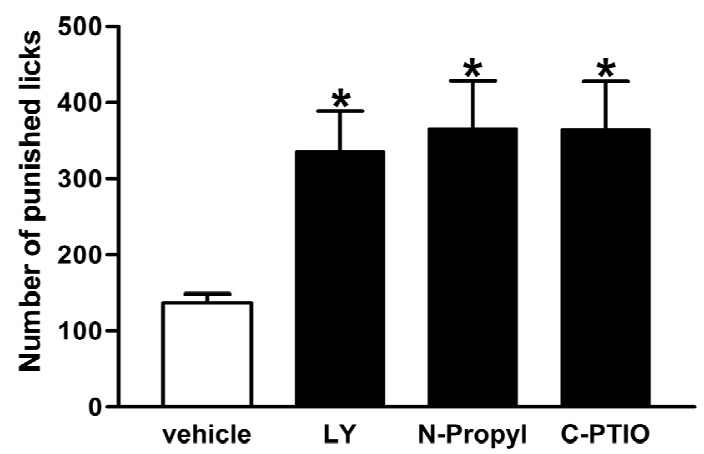

Figure 2. Effects of bilateral microinjection of $200 \mathrm{~nL}$ of vehicle, $4 \mathrm{nmol}$ of LY235959 (LY), $0.04 \mathrm{nmol}$ of N-Propyl or $1 \mathrm{nmol}$ of c-PTIO ( $n=8$, each treatment) in the vMPFC on the number of punished licks in the Vogel conflict test. Columns represent the mean and bars the SEM, $* \boldsymbol{P}<0.05$ (compared to vehicle group), Dunnett's post-test.

increased the number of punished licks $(F 3,22=9.7, P<$ $0.01)$ and the total number of licks $(F 3,20=9.7, P<0.01)$ when compared to the vehicle group $(n=8$, Figure 2). No changes were observed when LY, N-Propyl or c-PTIO $(n=9$ each treatment) were microinjected into vMPFC surrounding structures such as the cingulate cortex area 1 , the corpus callosum and the tenia tecta $(F 3,16=9.7, P>$ 0.05 , Figure 3).

In the control test in which no shocks were delivered, the number of licks were not different between the groups $(F 3,32=0.9, P>0.05$, Figure 4$)$, indicating that vMPFC inhibition did not influence water consumption $(n=5$, each treatment).

\subsection{Drug Effects in the Tail-Flick Test}

The repeated measures ANOVA revealed a significant drug $\times$ time interaction $(F 20,114=2.8, P<0.001)$. Moreover, there was a significant drug effect $(\mathrm{F} 4,114=19.6$, $P<0.001)$ and a time effect $(F 5,114=10.7, P<0.001)$. Post-hoc comparisons indicated that the withdrawal latencies were significant greater than vehicle at 10,20,30 and $40 \mathrm{~min}$ after the injection in the group receiving morphine $(n=5, P<0.001)$. No effect was observed after LY, N-Propyl or c-PTIO bilateral microinjection into the $\operatorname{vMPFC}(n=5$, each treatment, Figure 5).

\section{Discussion}

The present study showed that NMDA receptors antagonism or reducing the NO synaptic concentration, inhibiting NO synthesis or scavenging NO, in the vMPFC induced an increase in the number of punished licks in the VCT, an anxiolytic-like effect, supporting previous results suggesting that these neurotransmitters, glutamate and NO, have an important role in control of anxiety by

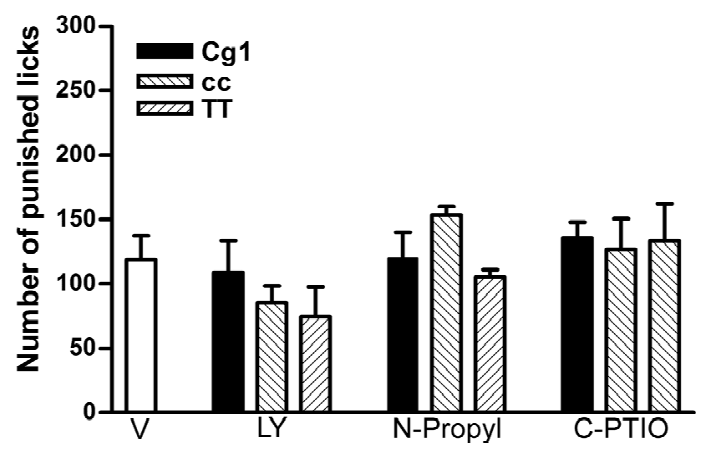

Figure 3. Effects of bilateral microinjection of $200 \mathrm{~nL}$ of vehicle, $4 \mathrm{nmol}$ of LY235959 (LY), $0.04 \mathrm{nmol}$ of N-Propyl or 1 nmol of c-PTIO $(n=9$, each treatment) outside the vMPFC on the number of punished licks in the Vogel conflict test. Columns represent the mean and bars the SEM. V- vehicle; Cg1 - cingulate cortex area 1; cc - corpus callosum and TT- tenia tecta.

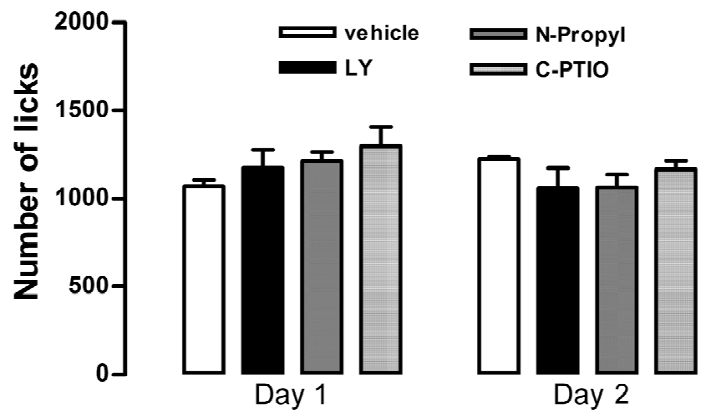

Figure 4. Effects of bilateral microinjection of $200 \mathrm{~nL}$ of vehicle, $4 \mathrm{nmol}$ of LY235959 (LY), $0.04 \mathrm{nmol}$ of $\mathrm{N}$-Propyl or $1 \mathrm{nmol}$ of c-PTIO ( $n=5$, each treatment) in the VMPFC of the rats submitted to evaluation of water consumption. Columns represent the means and bars the S.E.M. of number of licks measured for each group in a $3 \mathrm{~min}$ period after $24 \mathrm{~h}$ (Day 1) and 48h (Day 2) of water deprivation.

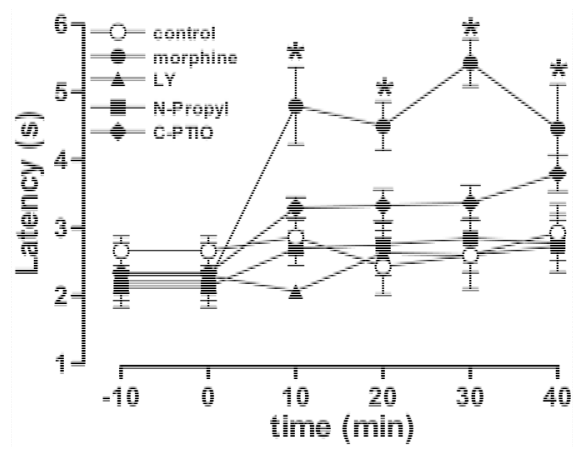

Figure 5. Time course of the effects of i.p. administration of vehicle or morphine $5 \mathrm{mg} / \mathrm{kg}$ or bilateral microinjections $200 \mathrm{~nL}$ of vehicle, $4 \mathrm{nmol}$ of LY235959 (LY), $0.04 \mathrm{nmol}$ of $\mathrm{N}$-Propyl or $1 \mathrm{nmol}$ of c-PTIO ( $n=5$, each treatment) in the vMPFC on the tail flick test. Each point represents the mean and bars the SEM for the latency of tail withdrawal, $* P<0.05$ compared to vehicle (ANOVA followed by Bonferroni's post hoc test). 
brain structures like the dorsolateral periaqueductal gray, inferior colliculus [25] and vMPFC [19]. Since these results could reflect non-specific interference with water consumption and/or nociceptive threshold [15], we also tested the effects of these drugs in these two parameters. The drugs, however, failed to change the number of unpunished licks and tail flick latency. Also, no effects were observed when the drugs were bilaterally injected into nearby structures $(\mathrm{Cg} 1$, TT or cc). These results, therefore, suggest that inactivation of these neurotransmitters in vMPFC induces effects to anxiety in the VCT.

The present results confirm our previous work, which supported a possible existence of a NMDA/NO pathway in the vMPFC involved with anxiety-responses observed in the contextual fear conditioning, since its NMDA receptors or NO blockade impaired the fear response, characterized by increased freezing behavior and autonomic activity [19]. Both glutamatergic terminals and NMDA receptors are present in the vMPFC of rats [26,27] and, during stress conditions, glutamate levels are increased in this cortical structure [18]. It is well known that in central nervous system acute activation of NMDA receptors results in an increase in NO synthesis [28] by the activation of neuronial isoforma of NO synthase (nNOS) and, as suggested by these studies, these interaction could also occur in the vMPFC. Thus, the modulation of this pathway in the vMPFC can be involved with control of anxiety behavior.

These results also agree with studies which employed systemic administration of NMDA antagonists. In this context, Plaznik and cols using noncompetitive or competitive NMDA receptor antagonists showed anxiolyticlike effect in the VCT [29]. In addition, the NMDA antagonist, MK801, attenuated anxious-like behavior induced by exposing rats to a live cat, suggesting the involvement of these receptors in the neural alterations mediating disrupting-behavior effect of severe stress [30]. Another NMDA antagonist, the CGP37849, retained its anxiolytic-like effect in the VCT after repeated systemic administration and it was also able to increase exploratory behavior not related to motor activity [31]. Together with our findings, these results could suggest that vMPFC is a brain site of action of NMDA antagonists after systemic administration.

The anxiolytic-like effect observed after blocking NMDA/NO in the vMPFC in the present study and in the previous one [19] corroborate previous findings showing that temporary inhibition of vMPFC with cobalt chloride induced an anxiolytic-like effect in the VCT and contextual fear conditioning $[13,17]$, supporting the view that the neurotransmitters glutamate and NO in the vMPFC are important to the modulation of anxiety. It is suggested that the anxiolytic-like effect induced by blocking
NMDA/NO in the vMPFC could be related only to anxiety induced by associative learned fear, like in the VCT and the contextual fear conditioning, since in animal models of unlearned innate fear, the elevated plus maze and the light-dark box, the reversible blockade of vMPFC induced anxiogenic-like effects [32]. The exact mechanism involved in the modulation of anxiety behavior by the NMDA/NO in the vMPFC is not entirely know, but could also involve other brain structures. The vMPFC projects to several regions related to autonomic and behavioral responses to an aversive stimulus, including the amygdaloid nuclei, hippocampus, dorsal raphe nuclei and dorsal periaqueductal gray $[33,34]$.

In agreement with the present and previous results, anxiolytic-like effects of GABA potentiation or glutamate antagonist have been reported after direct drug injection into most of these structures (for review, see [35]. Thus, it is possible that the bloking of the NMDA/NO in the vMPFC could also leads to inhibition of excitatory projections or desinhibition of inhibitory projections to some of that structures related to induction of behavioral responses to an aversive stimulus. In addition to simply inhibit/desinhibit brain structures linked to vMPFC, another explanation could be based on vMPFC activity, which has been proposed to reflect an interaction between cognitive processing and emotional state $[14,36]$. It is well known that new environments are sources of ambiguous stimuli and potential dangers. In the VCT, as in the contextual fear conditioning, where the source of danger is well defined, drinking spout in the VCT, the local vMPFC inhibition of NMDA/NO, with consequent inhibition of glutamate and NO neurotransmission, would reduces the emotional impact of the threatening stimulus, leading to an anxiolytic effect. It is speculated, therefore, that inhibition of this possible pathway in the vMPFC of animals submitted to animal models of unlearned innate fear could induce opposed effects, but this still have to be addressed.

\section{Conclusions}

In conclusion, the findings of the present work support the view that NMDA receptors and NO presents in the vMPFC could participate in the modulation of anxiety behavior elicited by associative learned fear.

\section{Acknowledgements}

The authors wish to thank to Laura H. A. de Camargo, Ivanilda A.C. Fortunato and José Carlos de Aguiar for technical support. S.F. Lisboa is recipients of a $\mathrm{PhD}$ fellowship from FAPESP (07/06999-9). Research supported by a grant from FAPESP (2009/03187-9), CNPq 
(470042/2009-5 and 305996/2008-8) and FAEPA.

\section{Conflicts of Interest}

The authors state that there are no conflicts of interests that relate to this research.

\section{References}

[1] M. Abbruzzese, L. Bellodi, S. Ferri and S. Scarone, "Frontal Lobe Dysfunction in Schizophrenia and Obsessive-Compulsive Disorder: A Neuropsychological Study," Brain and Cognition, Vol. 27, No. 2, 1995, pp. 202-212. doi:10.1006/brcg.1995.1017

[2] L. R. Baxter Jr., J. M. Schwartz, B. H. Guze, K. Bergman and M. P. Szuba, "PET Imaging in Obsessive Com- pulsive Disorder with and without Depression," Journal of Clinical Psychiatry, Vol. 51, Suppl. 61-69, 1990, discussion 70 .

[3] A. L. Malizia, "What Do Brain Imaging Studies Tell Us About Anxiety Disorders? Journal of Psychopharmacology, Vol. 13, No. 4, 1999, pp. 372-378. doi:10.1177/026988119901300418

[4] C. H. Beck and H. C. Fibiger, "Conditioned Fear-Induced Changes in Behavior and in the Expression of the Immediate Early Gene C-Fos: With and without Diazepam Pretreatment," The Journal of Neuroscience, Vol. 15, No. 1, 1995, pp. 709-720.

[5] L. Lacroix, S. Spinelli, C. A. Heidbreder and J. Feldon, "Differential Role of the Medial and Lateral Prefrontal Cortices in Fear and Anxiety," Behavioral Neuroscience, Vol. 114, No. 6, 2000, pp. 1119-1130. doi:10.1037/0735-7044.114.6.1119

[6] A. A. Shah and D. Treit, "Excitotoxic Lesions of the Medial Prefrontal Cortex Attenuate Fear Responses in the Elevated-Plus Maze, Social Interaction and Shock Probe Burying Tests," Brain Research, Vol. 969, No. 1-2, 2003, pp. 183-194. doi:10.1016/S0006-8993(03)02299-6

[7] A. A. Shah and D. Treit, "Infusions of Midazolam into the Medial Prefrontal Cortex Produce Anxiolytic Effects in the Elevated Plus-Maze and Shock-Probe Burying Tests," Brain Research, Vol. 996, No. 1, 2004, pp. 31-40. doi:10.1016/j.brainres.2003.10.015

[8] R. M. Sullivan and A. Gratton, "Behavioral Effects of Excitotoxic Lesions of Ventral Medial Prefrontal Cortex in the Rat Are Hemisphere-Dependent," Brain Research, Vol. 927, No. 1, 2002, pp. 69-79. doi:10.1016/S0006-8993(01)03328-5

[9] A. L. Jinks and I. S. McGregor, "Modulation of AnxietyRelated Behaviours Following Lesions of the Prelimbic or Infralimbic Cortex in the Rat," Brain Research, Vol. 772, No. 1-2, 1997, pp. 181-190. doi:10.1016/S0006-8993(97)00810-X

[10] L. B. Resstel and F. M. Correa, "Involvement of the Medial Prefrontal Cortex in Central Cardiovascular Modulation in the Rat," Autonomic Neuroscience, Vol. 126-127, 2006, pp. 130-138. doi:10.1016/j.autneu.2006.02.022

[11] L. B. Resstel, K. B. Fernandes and F. M. Correa, "AlphaAdrenergic and Muscarinic Cholinergic Receptors Are Not Involved in the Modulation of the Parasympathetic Baroreflex by the Medial Prefrontal Cortex in Rats," Life Sciences, Vol. 77, No. 13, 2005, pp. 1441-1451. doi:10.1016/j.lfs.2005.03.012

[12] R. Dias, J. P. Aggleton, "Effects of Selective Excitotoxic Prefrontal Lesions on Acquisition of Nonmatching-and Matching-to-Place in the T-Maze in the Rat: Differential Involvement of the Prelimbic-Infralimbic and Anterior Cingulate Cortices in Providing Behavioural Flexibility," European Journal of Neuroscience, Vol. 12, No. 12, 2000, pp. 4457-4466. doi:10.1046/j.0953-816X.2000.01323.x

[13] L. B. Resstel, S. R. Joca, F. G. Guimaraes and F. M. Correa, "Involvement of Medial Prefrontal Cortex Neu- rons in Behavioral and Cardiovascular Responses to Contextual Fear Conditioning," Neuroscience, Vol. 143, No. 2, 2006, pp. 377-385. doi:10.1016/j.neuroscience.2006.08.002

[14] P. Flores and R. Pellon, "Antipunishment Effects of Diazepam on Two Levels of Suppression of Schedule-Induced Drinking in Rats," Pharmacology Biochemistry and Behavior, Vol. 67, No. 2, 2000, pp. 207-214. doi:10.1016/S0091-3057(00)00313-0

[15] M. J. Millan and M. Brocco, "The Vogel Conflict Test: Procedural Aspects, Gamma-Aminobutyric Acid, Glutamate and Monoamines," European Journal of Pharmacology, Vol. 463, No. 1-3, 2003, pp. 67-96. doi:10.1016/S0014-2999(03)01275-5

[16] J. R. Vogel, B. Beer and D. E. Clody, "A Simple and Reliable Conflict Procedure for Testing Anti-Anxiety Agents," Psychopharmacologia, Vol. 21, 1971, pp. 1-7. doi:10.1016/S0014-2999(03)01275-5

[17] L. B. Resstel, R. F. Souza and F. S. Guimaraes, "Anxiolytic-Like Effects Induced by Medial Prefrontal Cortex Inhibition in Rats Submitted to the Vogel Conflict Test," Physiology \& Behavior, Vol. 93, No. 1-2, 2008, pp. 200205. doi:10.1016/i.physbeh.2007.08.009

[18] B. Moghaddam, "Stress Preferentially Increases Extraneuronal Levels of Excitatory Amino Acids in the Prefrontal Cortex: Comparison to Hippocampus and Basal Ganglia," Journal of Neurochemistry, Vol. 60, No. 5, 1993, pp. $1650-1657$. doi:10.1111/j.1471-4159.1993.tb13387.x

[19] L. B. Resstel, F. M. Correa and F. S. Guimaraes, "The Expression of Contextual Fear Conditioning Involves Activation of an NMDA Receptor-Nitric Oxide Pathway in the Medial Prefrontal Cortex," Cerebral Cortex, Vol. 18, No. 9, 2008, pp. 2027-2035. doi: $10.1093 /$ cercor/bhm 232

[20] S. F. Lisboa, L. B. Resstel, D. C. Aguiar and F. S. Guimaraes, Activation of cannabinoid CB1 Receptors in the Dorsolateral Periaqueductal Gray Induces Anxiolytic Effects in Rats Submitted to the Vogel Conflict Test," European Journal of Pharmacology, Vol. 593, No. 1-3, 2008, pp. 73-78. doi:10.1016/j.ejphar.2008.07.032

[21] L. B. Resstel and F. M. Correa, "Injection of 1-Glutamate into Medial Prefrontal Cortex Induces Cardiovascular Responses through NMDA Receptor-Nitric Oxide in 
Rat," Neuropharmacology, Vol. 51, No. 1, 2006, pp. 160167. doi:10.1016/j.neuropharm.2006.03.010

[22] L. B. Resstel and F. M. Correa, "Medial Prefrontal Cortex NMDA Receptors and Nitric Oxide Modulate the Parasympathetic Component of the Baroreflex," European Journal of Neuroscience, Vol. 23, No. 2, 2006, pp. 481-488.doi:10.1111/j.1460-9568.2005.04566.x

[23] H. Q. Zhang, W. Fast, M. A. Marletta, P. Martasek and R. B. Silverman, "Potent and Selective Inhibition of Neuronal Nitric Oxide Synthase by N omega-propyl-L-arginine," Journal of Medicinal Chemistry, Vol. 40, No. 24, 1997, pp. 3869-3870. doi:10.1021/jm970550g

[24] R. F. Tavares, L. B. Resstel and F. M. Correa, "Interaction between Glutamatergic and Nitrergic Mechanisms Mediating Cardiovascular Responses to L-Glutamate Injection in the Diagonal Band of Broca in Anesthetized Rats," Life Science, Vol. 81, No. 10, 2007, pp. 855-862. doi:10.1016/j.lfs.2007.07.028

[25] F. S. Guimaraes, V. Beijamini, F. A. Moreira, D. C Aguiar and A. C. de Lucca, "Role of Nitric Oxide in Brain Regions Related to Defensive Reactions," Neuroscience \& Biobehavioral Reviews, Vol. 29, No. 8, 2005, pp. 1313-1322. doi:10.1016/j.neubiorev.2005.03.026

[26] J. Gigg, A. M. Tan and D. M. Finch, "Glutamatergic Hippocampal Formation Projections to Prefrontal Cortex in the Rat Are Regulated by Gabaergic Inhibition and Show Convergence with Glutamatergic Projections from the Limbic Thalamus," Hippocampus, Vol. 4, No. 2, 1994, pp. 189-198. doi:10.1002/hipo.450040209

[27] M. M. Nicolle and M. G. Baxter, "Glutamate Receptor Binding in the Frontal Cortex and Dorsal Striatum of Aged Rats with Impaired Attentional Set-Shifting," European Journal of Neuroscience, Vol. 18, No. 12, 2003, pp. 33353342. doi:10.1111/j.1460-9568.2003.03077.x

[28] H. Y. Yun, V. L. Dawson and T. M. Dawson, "Nitric Oxide in Health and Disease of the Nervous System," Molecular Psychiatry, Vol. 2, No. 4, 1997, pp. 300-310. doi:10.1038/sj.mp.4000272
[29] A. Plaznik, W. Palejko, M. Nazar and M. Jessa, "Effects of Antagonists at the NMDA Receptor Complex in Two Models of Anxiety," European Neuropsychopharmacology, Vol. 4, No. 4, 1994, pp. 503-512. doi:10.1016/0924-977X(94)90299-2

[30] R. E. Adamec, P. Burton, T. Shallow and J. Budgell, "NMDA Receptors Mediate Lasting Increases in Anxiety-Like Behavior Produced by the Stress of Predator Exposure-Implications for Anxiety Associated with Posttraumatic Stress Disorder," Physiology \& Behavior, Vol. 65, No. 4-5, 1999, pp. 723-737. doi:10.1016/S0031-9384(98)00226-1

[31] M. Jessa, M. Nazar, A. Bidzinski and A. Plaznik, "The Effects of Repeated Administration of Diazepam, MK801 and CGP 37849 on Rat Behavior in Two Models of Anxiety," European Neuropsychopharmacology, Vol. 6, No. 1, 1996, pp. 55-61. doi:10.1016/0924-977X(95)00068-Z

[32] S. F. Lisboa, M. F. Stecchini, F. M. Correa, F. S. Guimaraes and L. B. Resstel, "Different Role of the Ventral Medial Prefrontal Cortex on Modulation of Innate and Associative Learned Fear," Neuroscience, Vol. 171, No. 3, pp. 760-768. doi:10.1016/j.neuroscience.2010.09.048

[33] G. D. Fisk and J. M. Wyss, "Descending Projections of Infralimbic Cortex That Mediate Stimulation-Evoked Changes in Arterial Pressure," Brain Research, Vol. 859, No. 1, 2000, pp. 83-95. doi:10.1016/S0006-8993(00)01935-1

[34] R. P. Vertes, "Differential Projections of the Infralimbic and Prelimbic Cortex in the Rat," Synapse, Vol. 51, No. 1, 2004, pp. 32-58. doi:10.1002/syn.10279

[35] M. J. Millan, "The Neurobiology and Control of Anxious States," Progress in Neurobiology, Vol. 70, No. 2, 2003, pp. 83-244. doi:10.1016/S0301-0082(03)00087-X

[36] K. A, Corcoran and G. J. Quirk, "Activity in Prelimbic Cortex Is Necessary for the Expression of Learned, But Not Innate, Fears," The Journal of Neuroscience, Vol. 27, No. 4, 2007, pp. 840-844. doi:10.1523/JNEUROSCI.5327-06.2007 